\title{
Comparison of Daily and Sub-Daily SWAT Models for Daily Streamflow Simulation in the Upper Huai River Basin of China
}

\author{
Xiaoying Yang ${ }^{a^{*}}$, Qun Liu ${ }^{b}$, Yi He ${ }^{c}$, Xingzhang Luo ${ }^{a}$, Xiaoxiang Zhang ${ }^{d^{*}}$ \\ ${ }^{a}$ Department of Environmental Science and Engineering, Fudan University, Shanghai, \\ 200433, China. \\ ${ }^{b}$ Zhumadian City Bureau of Environmental Protection, Zhumadian,463000, China. \\ ${ }^{\mathrm{c}}$ Tyndall Centre for Climate Change Research, School of Environmental Sciences, \\ University of East Anglia, Norwich, United Kingdom. \\ ${ }^{\mathrm{d}}$ Institute of Geographical Information Science \& Engineering, Hohai University, Nanjing, \\ 210098, China. \\ *Email: xiaoying@fudan.edu.cn. Phone: 0086-21-65642192. Fax: 0086-21-65642948. \\ *Email: xiaoxiang@x-gis.com.cn. Phone: 0086-25-83787234. Fax: 0086-25-83787234.
}

\begin{abstract}
Despite the significant role of precipitation in the hydrological cycle, few studies have been conducted to evaluate the impacts of the temporal resolution of rainfall inputs on the performance of SWAT (soil and water assessment tool) models in large-sized river basins. In this study, both daily and hourly rainfall observations at 28 rainfall stations were used as inputs to SWAT for daily streamflow simulation in the Upper Huai River Basin. Study results have demonstrated that the SWAT model with hourly rainfall inputs performed better than the model with daily rainfall inputs in daily streamflow simulation, primarily due to its better capability of simulating peak flows during the flood season. The sub-daily SWAT model estimated that $58 \%$ of streamflow was contributed by baseflow compared to $34 \%$ estimated by the daily model. Using the future daily and three-hour precipitation projections under the RCP (Representative Concentration Pathways) 4.5 scenario as inputs, the sub-daily SWAT model predicted a larger amount of monthly maximum daily flow during the wet years than the daily model. The differences between the daily and sub-daily SWAT model simulation results indicated that temporal rainfall resolution could have much impact on the simulation of hydrological process, streamflow, and consequently pollutant transport by SWAT models. There is an imperative need for more studies to examine the effects of temporal rainfall resolution on the simulation of hydrological and water pollutant transport processes by SWAT in river basins of different environmental conditions.
\end{abstract}




\section{Introduction}

Precipitation is one critical factor affecting the hydrological processes of river basins. One important research question in hydrology is how the spatial and temporal structure of precipitation affects the surface and groundwater movement in river basins (Paschalis et al. 2014). There have been a number of studies evaluating the impacts of rainfall variability on runoff mostly through numerical experiments. Most of these previous studies are focused on examining the impacts of the spatial resolution of rainfall inputs (e.g. Moriasi and Starks 2010; Masih et al. 2011; Wagner et al. 2012; Yoon et al. 2014; Wang et al. 2015), while few examine the impacts of the temporal resolution of rainfall observations especially in the context of large-sized river basins.

The Soil and Water Assessment Tool (SWAT) model is a basin-scale, physically-based, continuous simulation model that has proven to be a useful tool for studying the water quantity and water quality issues of the basins of a wide range of scales and environmental conditions around the world (Arnold et al. 2014). Regardless of their ultimate objectives, adequate simulation of the targeted watershed's hydrologic balance is foundational for all SWAT applications. Gassman et al. (2007) gave an extensive review of 115 SWAT hydrologic studies, and concluded that their daily prediction results were generally poorer than monthly and annual predictions except in a few cases. They attributed the weaker results of some studies to inadequate spatial rainfall representation, inaccuracy in stream flow measurements, lack of model calibration, and relatively short calibration and validation periods. In the past few years, there has been much increase in using SWAT for daily hydrological simulations. Although the strongest results are still mostly reported by studies of annual and monthly time steps, there has been a trend of increase in the number of successful SWAT applications at the daily time step (Gassman et al. 2014).

Many statistics are available to evaluate the SWAT simulation results. Nevertheless, the most widely used statistics have been the regression correlation coefficient $\left(\mathrm{R}^{2}\right)$ and the Nash-Sutcliffe model efficiency (NSE) coefficient. The $\mathrm{R}^{2}$ value ranges from 0 to 1 and indicates the percentage of variance in measured data accounted for by the variance in the simulated results. The NSE value ranges from $-\infty$ to 1 , and measures how well the simulated versus observed data match the 1:1 line. To date, absolute criteria for judging model 
performance have yet to be established. Generally, NSE values greater than 0.75 indicate very good performance, while values lower than 0.36 indicate unsatisfactory performance, and the values in between indicate satisfactory performance (Krause et al. 2005).

Table 1 summarized a number of recent SWAT simulations of daily streamflow and their $\mathrm{R}^{2}$ and/or NSE statistics. The results of most of the applications could be considered as satisfactory except a few with very good or unsatisfactory results. For example, Fohrer et al. (2014) used SWAT to assess the environmental fate of the commonly used herbicides flufenacet and metazachlor in the $50 \mathrm{~km}^{2}$ Kielstau watershed in Northern Germany. They obtained very good simulation results for daily stream flow with an NSE value of 0.83 and 0.76 for the calibration and validation period, respectively. Some SWAT applications have attributed their unsatisfactory performance in daily simulation to SWAT's algorithms, and proposed modifications accordingly. For example, Lv et al. (2014) modified the algorithm for calculating the peak flow rate and peak time in SWAT and got better simulation results for the Pengjiahe Irrigation District in Hubei province of China.

Despite SWAT's capability to incorporate rainfall inputs of higher temporal resolution such as sub-daily and sub-hourly rainfalls, the majority of previous SWAT studies have been utilizing daily rainfall inputs. Few studies have been conducted to evaluate the impacts of the temporal resolution of rainfall inputs on the SWAT model's daily streamflow simulation performance. The limited SWAT studies with rainfall inputs of higher temporal resolution have been mostly conducted in small-sized watersheds (Jeong et al. 2011), and their results have been contradictory. Maharjan et al. (2013) compared the performance of the SWAT models in simulating the amount of runoff from a 0.8 ha field-sized agricultural watershed with 15-min, 2-h, 6-h, and 12-h precipitation data, and concluded that the models generally yielded a better performance with the increase in the temporal resolution of precipitation. Kannan et al. (2007), on the other hand, found that their SWAT models' simulation results of daily runoff using daily precipitation data were consistently better than those using 30-min precipitation data at a small 141.5 ha watershed in England.

Located about the mid-way between the Yellow River and Yangtze River, the Huai River is one of the major rivers in China. Originated from the Tongbai Mountains of Henan province, the Huai River flows $1000 \mathrm{~km}$ through four provinces and drains an area of $174,000 \mathrm{~km}^{2}$. Located in the transition zone between the northern and southern climates in 
China and subjected to the great influence of monsoon, the Huai River Basin is prone to the extreme events of both drought and flood. It is estimated that there have been 63 extreme floods and 46 extreme droughts in the Huai River Basin between 1470 and 2010.

Establishing adequate hydrological models to understand the hydrological processes and evaluate the potential impacts of future climate change are of great importance to the sustainable management of the water resources and developing programs for climate change adaptation and mitigation in the basin.

There have been some SWAT applications to simulate the monthly streamflow in the Huai River Basin as well as its sub-basins. For example, Zhang et al. (2013) developed a SWAT model to simulate the monthly stream flow at 45 stations from 1961 to 2000 in the Upper and Middle Huai River Basin. For 19 hydrological stations unregulated by reservoirs, their SWAT models' NSE values ranged from 0.40 to 0.89 for calibration and from 0.19 to 0.80 for validation. For 8 stations moderately regulated by reservoirs, NSE values ranged from 0.40 to 0.88 for calibration and from 0.46 to 0.78 for validation. For 12 stations highly regulated by reservoirs, NSE values ranged from 0.15 to 0.78 for calibration and -0.73 to 0.63 for validation. Shi et al. (2013) used SWAT to simulate the monthly river flow at the Xixian sub-basin with a drainage area of $10191 \mathrm{~km}^{2}$ from 1984 to 2005 , and obtained an NSE value of 0.90 and 0.91 for the calibration and validation period, respectively.

In this study, SWAT was used to simulate the daily streamflow at the Shakou hydrological station in the Upper Huai River Basin with a total drainage area of $5803 \mathrm{~km}^{2}$. Both daily and sub-daily rainfall observations at 28 rainfall stations were used as the model inputs to evaluate the impacts of the temporal resolution of rainfall on the daily simulation performance of the SWAT model in this large-sized basin. Projections of daily and sub-daily rainfall till 2050 by a regional climate model were then used as inputs to the SWAT models to examine the impacts of the temporal resolution of rainfall on the forecasts of future streamflow.

\section{Study region and methodology}

\subsection{Study region}

Located above the Shakou hydrological station of the upstream Huai River, the Ru River Basin drains a total area of $5803 \mathrm{~km}^{2}$ (Fig. 1). With hills in the west and plains in the east, surface elevation in the basin ranges from $41 \mathrm{~m}$ to $977 \mathrm{~m}$. Situated in the transition zone 
between the northern subtropical and warm temperate climate, the basin is characterized with four distinct seasons. Its annual mean temperature falls between $14.6^{\circ} \mathrm{C}$ and $15^{\circ} \mathrm{C}$, annual precipitation between $860 \mathrm{~mm}$ and $980 \mathrm{~mm}$, and annual solar radiation between 112 and $120 \mathrm{kcal} / \mathrm{cm}^{2}$. Most of its precipitation occurs in the summer months from June to August.

The Ru River Basin is predominantly an agricultural watershed, with farmland, woodland, and grassland accounting for $65.6 \%, 14.5 \%$, and $5.1 \%$ of its land coverage, respectively. Nearly $90 \%$ of the basin is dominated by three soil types, which are yellow-cinnamon soil, lime concretion black soil, and calcareous fluvo-aquic soil in an order of decreasing distribution area (Fig. 2). All of the three types of soils are generally high in clay and silt contents with poor soil permeability. Meanwhile, they also tend to have low contents of organic matters and soil nutrients such as nitrogen and phosphorous. Despite the less ideal soil properties for agricultural cultivation, the availability of sufficient moisture and heat allows the widespread double-cropping practice (mainly wheat-corn rotation) in the basin, and the region has long been recognized as one important "granary" of China.

\subsection{Data sources}

Topographic, land use/land cover (LULC), soil, and hydro-meteorological data used for developing the SWAT model in the Ru River Basin were summarized in Table 2. The $25 \mathrm{~m}$ Digital Elevation Model (DEM) data was obtained from the National Geomatics Center of China. The 2005 LULC map $(1: 100,000)$ was derived from the classification of the Landsat-TM images by Chinese Academy of Science according to the Chinese National Standard of Land Use Classifications, which was further classified into the standard LULC categories of SWAT. The spatial distribution of soil types as well as some physical and chemical properties of the soil layers was extracted from the soil databases of Nanjing Institute of Soil Science (Shi et al. 2004; Yu et al. 2007a; Yu et al. 2007b; Shi et al. 2010). In addition, the SPAW( Soil - Plant - Atmosphere - Water) software was used to estimate the available water capacity and soil carbon content of the soil layers (Saxton and Willey 2005), and the nutrient contents (nitrate, organic nitrogen, labile phosphorous, and organic phosphorous) of the soil layers were obtained from local soil survey reports (Henan Province Soil Survey Office, 1995).

To collect information on local crop management practices, face-to-face interviews with 
116 farmers in 16 villages were conducted in the $\mathrm{Ru}$ River Basin based on a pre-constructed questionnaire. The interview results showed that the local farmers had been mostly practicing the wheat-corn rotation with rather homogeneous crop management practices. Generally, corn is planted in early June and harvested at the end of September, while wheat is planted in early October and harvested at the end of May. For corn, around $750 \mathrm{~kg} / \mathrm{ha}$ of compound fertilizers and $188 \mathrm{~kg} / \mathrm{ha}$ of urea are applied during planting, and an additional $150 \mathrm{~kg} / \mathrm{ha}$ of urea is applied in July. For wheat, around $750 \mathrm{~kg} / \mathrm{ha}$ of compound fertilizers and $94 \mathrm{~kg} / \mathrm{ha}$ of urea are applied during planting, and an additional $94 \mathrm{~kg} / \mathrm{ha}$ of urea is applied in the subsequent February.

Daily meteorological records on precipitation, maximum and minimum temperature, sunshine hours, relative humidity, and wind speed at the Zhumadian weather station from 1961 to 2011 were acquired from Chinese Meteorological Administration. Based on the historical weather data, the statistical parameters required by the SWAT weather generator were then calculated. The observed daily sunshine hours were also used to calculate daily solar radiation using the Angstrom-Prescott equation (Prescott 1940) whose empirical parameter values were obtained from Zuo et al. (1963). In addition, data on daily rainfall throughout the year and hourly rainfall in the flood season (May to September) at 28 rainfall stations from 2001 to 2011 were extracted from the annual reports on the Huai River Basin by Chinese Ministry of Water Resources. Daily streamflow at three hydrological stations (Lixin, Luzhuang, and Shakou) and daily outflow from three major reservoirs (Banqiao, Boshan, and Suyahu) from 2005 to 2011 were also extracted from the annual reports (Fig. 1).

Hydrological models including SWAT have been frequently used to assess the potential impacts of climate change on the hydrological cycles of global and regional scales by using the projections of future climatic conditions as their weather forcings (Jha and Gassman 2014; Li et al. 2014; Praskievicz and Bartlein 2014). There are a variety of methods to obtain the downscaled rainfall projections suitable for regional impact studies. For the Huai River Basin, some studies downscaled the monthly GCM precipitation projections to daily resolution using weather generators such as BCC/RCG-WG (Du et al. 2014) and LARS-WG (Duan and Mei 2014), while other studies utilized the outputs from regional climate models such as the CCLM (COSMO Model in Climate Mode) (Gao et al. 2014) and PRECIS (Providing Regional Climates for Impacts Studies) (Lu et al. 2013; Hu et al. 2014) models. 
Nevertheless, most of these studies only utilized the projected rainfall data of daily resolution.

In this study, projections of future precipitation and temperature till 2050 for the study region were extracted from the HadGEM3-RA outputs provided by the CORDEX (Coordinated Regional Climate Downscaling Experiment) -East Asia. The CORDEX initiative was created by the Task Force for Regional Climate Downscaling (TFRCD) of the World Climate Research Program to generate regional climate change projections for various terrestrial regions within the timeline of the IPCC Fifth Assessment Report and beyond. CORDEX-East Asia is the East-Asian branch of the CORDEX initiative that produces ensemble climate simulations based on multiple dynamical and statistical downscaling models forced by various global climate models.

The HadGEM3-RA model is based on the global atmospheric HadGEM3 of the Met Office Hadley Centre (MOHC). The number of grid points in the HadGEM3-RA model is 220 (west-east) by 183 (north-south), with a horizontal resolution of 0.44 degree (approximately 50km). Configuration of HadGEM3-RA is almost same as the HadGEM3-A, except that the dynamic settings were taken from the operational limited area model.

Detailed descriptions of the HadGEM model could be found in Davies et al. (2005) and Martin et al. (2006). In this study, the daily and three-hour outputs of precipitation, and the daily outputs of minimum and maximum temperature of the HadGEM3-RA model under the Representative Concentration Pathways (RCP) 4.5 scenario were used.

2.3 Spatiotemporal variability of precipitation

There have been large spatial and temporal variations in precipitation in the Ru River Basin between 2001 and 2011 (Fig. 3). Annual mean precipitation of the 28 rainfall stations in the wettest year of 2003 was $1317 \mathrm{~mm}$, more than twice the amount of $583 \mathrm{~mm}$ in the driest year of 2001. The range of annual precipitation among the 28 stations remained above $320 \mathrm{~mm}$ throughout the 11-year period, with its coefficient of variation fluctuating between 0.1 and 0.2. Fig. 4 showed the spatial distribution of the average annual precipitation between 2001 and 2011. Generally, annual precipitation tended to be the lowest in the eastern and northwestern parts of the basin, higher in the southwestern part, and the highest in the middle.

Despite the considerable variability in the spatiotemporal distribution of precipitation in 
the Ru River Basin, its monthly precipitation exhibited a consistent pattern of concentration in the so-called flood season of May to September (Fig. 3). On the average, monthly precipitation from May to September was 92, 121, 255, 141, and $70 \mathrm{~mm}$ between 2001 and 2011 , which together could account for $73.8 \%$ of annual precipitation. Meanwhile, there was much more variability in precipitation in the flood season.

\subsection{SWAT model setup}

For this study, the latest version of SWAT2012 was used. In SWAT, the Penman-Monteith equation was used to calculate potential evaportranspiration, the rainfall-runoff routing was computed using the SCS curve number method in the daily model and the Green \& Ampt infiltration method in the sub-daily model, and the channel routing was calculated according to the variable storage coefficient method.

The Arc SWAT 2012 interface was used to prepare the input files for SWAT. The $25 \mathrm{~m}$ DEM was used to delineate the sub-basins and river networks. Due to the continuing and extensive modifications to the study region's natural drainage system, the river burn-in option was used to generate the river networks based on the 1:250,000 river network dataset obtained from the Computer Network Information Center of Chinese Academy of Science. Using a threshold area of 8000 ha, a total of 55 sub-basins were delineated (Fig. 1), which were further divided into 394 hydrological response units (HRUs) with similar characteristics of LULC, soils, and slopes.

There are three major reservoirs in the Ru River Basin: Banqiao, Boshan, and Suyahu. The Suyahu reservoir is the biggest with a maximum storage capacity of 1.66 billion $\mathrm{m}^{3}$, compared to 0.66 billion $\mathrm{m}^{3}$ of the Banqiao reservoir and 0.40 billion $\mathrm{m}^{3}$ of the Boshan reservoir. In SWAT, a reservoir is simulated as a water body with inflow, outflow, and change in storage. Although not suitable for real-time reservoir operation, the reservoir module of SWAT does provide sufficient accuracy for water balance assessment, especially when data on the reservoir outflows are available (Wang and Xia 2010). In this study, the three reservoirs were all simulated with their measured daily outflow rates.

The SWAT models for the Ru River Basin were set up with daily and hourly rainfall inputs, respectively. Since they were only available for the flood season (May to September), hourly rainfall data were estimated by assuming a uniform distribution in daily rainfall for the other seven months. The SUFI-2 algorithm built in the Soil and Water Assessment Tool 
Calibration and Uncertainty Procedure (SWAT-CUP) (Abbaspour 2011) was used for both the calibration and validation of the SWAT models. After a four-year warming-up period, daily stream flow records at the three hydrological stations from 2005 to 2008 were used for calibration, while the records from 2009 to 2011 were used for validation.

2.5 Model uncertainty analysis

Hydrological models are subjected to many types of uncertainties such as conceptual model uncertainty, input uncertainty, and parameter uncertainty. Different methodologies and algorithms have been developed to assess uncertainties in hydrological modeling, such as the Generalized Likelihood Uncertainty Estimation (GLUE), Parameter Solution (ParaSol), Sequential Uncertainty Fitting (SUFI2), and Markov chain Monte Carlo (MCMC) methods, which have been applied and sometimes compared in Chinese river basins such as the Chaohe Basin (Yang et al. 2008), Lake Dianchi Basin (Zhou et al. 2014), and Wenjing River Watershed (Wu and Chen 2015).

The SUFI-2 algorithm uses the Latin hypercube sampling procedure, along with a global search algorithm that examines the behavior of the objective function by analyzing the Jacobian and Hessian matrices to progressively reduce the uncertainty in model parameters (Abbaspour et al. 2004). It accounts for all sources of uncertainties (including the conceptual model uncertainty, input uncertainty, and parameter uncertainty) for hydrological modeling by two measures known as the P-factor and the R-factor. The P-factor refers to the percentage of measured data bracketed by the $95 \%$ prediction uncertainty (95PPU), which is calculated at the $2.5 \%$ and $97.5 \%$ levels of the cumulative distribution of the output variable obtained through Latin hypercube sampling. The R-factor refers to the average thickness of the 95PPU band divided by the standard deviation of the measured data. Theoretically, the P-factor ranges from 0 to 1 , and the R-factor ranges from 0 to infinity. The goodness of calibration and prediction uncertainty is judged on the basis of closeness of the P-factor to 1 (i.e. all observations bracketed by the $95 \%$ prediction uncertainty) and the R-factor to 1 (i.e. achievement of rather small uncertainty band). A larger P-factor can often be achieved at the expense of a larger R-factor, and a balance must be reached between the two.

\section{Results and discussion}

3.1 Parameter comparison between the daily and sub-daily SWAT models 
Table 3 listed the 16 parameters included in the calibration and validation of both the daily and sub-daily SWAT models of the Ru River Basin. For the parameter Alpha_BF, its calibration bounding limits were estimated based on the historical daily discharge records of the hydrological stations using the baseflow filter program (Arnold and Allen 1999). Based on the daily discharge records at the three hydrological stations, the SWAT-CUP program was used to calibrate both the daily and sub-daily models with several iterations of 1000 simulations. Because of its proximity to the massive and highly controlled Suyahu reservoir with a storage capacity of 1.66 billion $\mathrm{m}^{3}$, discharge at the downstream Shakou station is much influenced by the outflows from the reservoir. To avoid the potential bias caused by the reservoir-influenced station, much more weight was given to the two upstream stations of Lixing and Luzhuang during calibration.

Table 4 compared the parameter calibration results between the daily and sub-daily models. At the beginning of the calibration, the same parameter ranges were used in the calibration of both models. Generally, parameters showed more sensitivity in the sub-daily models than the daily models. At the beginning of the calibration, seven parameters (CN2_URML, CANMX_FRST, GW_DELAY, GWQMN, REVAPMN,SOL_K,CH_N2) were not significantly sensitive at the 0.10 level in the daily model compared to two parameters (CANMX_AGRR and CH_N1) in the sub-daily model. After calibration, all parameters were still sensitive except $G W Q M N$ and $C H \_N 2$ in the sub-daily model, while only six parameters $\left(C N 2 \_F R S T, S U R L A G, E P C O, A L P H A \_B F, E S C O, C H \_N 1\right)$ remained significantly sensitive in the daily model.

Comparing the calibrated parameter values between the daily and sub-daily models indicated that their differences mainly lay in the parameters related to surface runoff and groundwater. In the calibrated sub-daily model, its larger moisture condition II curve numbers led to higher surface runoff potentials; its larger $G W \_D E L A Y$ value caused more delay for soil water to reach the shallow aquifer; and its larger $G W \_R E V A P$ and lower REVAPMN values enabled more groundwater to diffuse upward and evaporate. These parameter differences seemed to indicate that the sub-daily model would predict more surface runoff and less baseflow contributing to river discharge than the daily model. However, water balance analysis of the Ru River Basin based on the two models yielded opposite results. The daily model estimated that $34 \%$ of the streamflow was contributed by 
baseflow compared to a larger estimate of $58 \%$ by the sub-daily model. The counterintuitive simulation results could be due to the different runoff estimation methods used by the two models. The daily model used the SCS curve number method, while the sub-daily model used the Green \& Ampt infiltration method. In addition, the baseflow filter program (Arnold and Allen 1999) gave an estimated range of 0.47-0.64 for baseflow contribution, which coincided with the sub-daily model results.

3.2 Model performance comparison between the daily and sub-daily SWAT models

Table 5 compared the performances of the daily and sub-daily SWAT models at the three hydrological stations for both the calibration (2005-2008) and validation (2009-2011) periods. As mentioned above, since the discharge at the Shakou station is highly influenced by the Suyahu reservoir, whose daily outflow rates were used as model inputs, both the daily and sub-daily models were able to simulate its discharge rates well with both $\mathrm{R}^{2}$ and NSE above 0.90 during the calibration and validation periods. At the upstream Lixin and Luzhuang stations, however, the sub-daily model has yielded much better performance than the daily model during both calibration and validation. At the Luzhuang station, for example, the $\mathrm{R}^{2}$ of the sub-daily model is 0.75 and 0.70 during the calibration and validation period, respectively, much higher than 0.47 and 0.27 of the daily model.

Fig. 5 showed the observed and simulated amount of daily discharge at the Lixin and Luzhuang stations throughout the modeling period. Fig. 6 compared the observed and simulated amount of peak flow for all of the 99 percentile stream discharge events at the two stations. Generally, the sub-daily model was able to simulate the peak flow rates better than the daily model, especially at the Luzhuang station. For example, on July 16 of 2010, daily discharge was simulated to be $14.8 \mathrm{~m}^{3} / \mathrm{s}$ and $27.8 \mathrm{~m}^{3} / \mathrm{s}$ by the daily and sub-daily model, respectively, compared to the observed amount of $31.3 \mathrm{~m}^{3} / \mathrm{s}$ at the Lixin station. Likewise, at the Luzhuang station, daily discharge was simulated to be $25.1 \mathrm{~m}^{3} / \mathrm{s}$ and $38.3 \mathrm{~m}^{3} / \mathrm{s}$ by the daily and sub-daily model, respectively, compared to the observed amount of $39.8 \mathrm{~m}^{3} / \mathrm{s}$ on July 18 of 2010. The better performance of the sub-daily model could be due to its ability to incorporate the highly concentrated rainstorm events. For example, the daily rainfall on July 16, 2010 was $113.4 \mathrm{~mm}$ at the Lixin rainfall station, $72.8 \%$ of which occurred in a four-hour period between 3 and $7 \mathrm{am}$. With hourly rainfall as inputs, the sub-daily model was able to pick up the high rainfall variability and encompassed it in its simulation of streamflows. 
In addition, the poorer streamflow simulation performance during the days with rainfalls of low to medium intensity also contributed to the low NSE and $\mathrm{R}^{2}$ of the daily model at the Luzhuang Station. Fig. 7 compared the observed and simulated amount of daily streamflow at the Luzhuang station on all of the raining days when daily streamflow observations fell between 1 and $50 \mathrm{~m}^{3} / \mathrm{s}$. It can be seen that the daily model tended to be more sensitive to low and medium rainfall events, hence yielding significantly higher streamflow estimates than observed in many cases. A close examination of the HRUs of the sub-basin contributing to the Luzhuang station showed that around half of its land was covered by forests on steep slopes (>10\%) and soils with high runoff potentials. Due to their conflicting impacts on runoff, the counterbalance among forestland, steep slope, and impermeable soils led to a complex pattern of rainfall-runoff responses under the rainfall of enormous variability in the sub-basin. Both Fig. 6 and Fig. 7 indicated that the daily SWAT model fell short of capturing the complex rainfall-runoff dynamics of the sub-basin by under-predicting streamflows during heavy storm events and over-predicting during the rainfall events of lower intensity.

While the sub-daily model yielded better simulations of daily streamflow, especially peak flow during the flood season, than the daily model, it incurred larger modeling uncertainties. At the beginning of the calibration when the parameter range was the same, the P-factor and R-factor were 0.39 and 0.34 for the Lixin Station in the sub-daily model compared to 0.53 and 0.39 in the daily-model. Likewise, the P-factor and R-factor were 0.71 and 0.40 for the Luzhuang Station in the sub-daily model compared to 0.92 and 0.43 in the daily-model.

3.3 Peak flow projection comparison between the daily and sub-daily SWAT models

Since the daily and sub-daily SWAT models have yielded considerable difference in the simulation of historical daily streamflow, especially peak flow, in the Ru River Basin, the two models were compared in their projections of peak flows till 2050 using the downscaled HadGEM3-RA outputs provided by the CORDEX-East Asia. In the HadGEM3-RA model, seven grid points were located either within or adjacent to the boundary of the Ru River Basin, whose precipitation and temperature projections were used as the inputs to the daily and sub-daily SWAT models. The weather generator of SWAT was used to generate the values for the other weather variables of solar radiation, relative humidity, and wind speed.

Since future reservoir outflow rates were not available, the three reservoirs were all 
simulated with the option of simulated target release in SWAT. Both the daily and sub-daily SWAT models were run with the HadGEM3-RA weather data from 2006 to 2050 with a five-year warming-up period. Due to the enormous impact of the Suyahu reservoir on the discharge at the outlet of the whole river basin, daily streamflow simulation results at the outlet of the sub-basin located along the River Ru and just above the Suyahu reservoir were used to make comparison between the daily and sub-daily models.

Fig. 8 compared the projected amount of monthly maximum daily discharge during the flood season (May to September) from 2011 to 20150 by the daily and sub-daily SWAT models. Both models have predicted a large intra-annual as well as inter-annual variation in monthly maximum daily discharge during the next few decades. The projected amount of monthly maximum daily discharge largely corresponded between the two models, except that the sub-daily model tended to project higher peak flows during the relatively wet years. For example, the simulated amount of maximum daily discharge in July by the sub-daily model surpassed the amount simulated by the daily model by 240, 164, 142, 137, and 126 $\mathrm{m}^{3} / \mathrm{s}$ in $2028,2018,2039,2023$, and 2034, respectively. This tendency of predicting higher peak flow by the sub-daily model was consistent with what was observed during the simulation of historical streamflow between 2005 and 2011.

\section{Conclusion}

SWAT model has been increasingly used to make daily simulations of the hydrological processes in basins of a wide range of scales. Despite the significant role of precipitation in the hydrological cycle, few studies have been conducted to examine the impacts of the temporal resolution of rainfall inputs on the SWAT model's performance in large-sized river basins. By comparing between the SWAT models with daily and hourly rainfall inputs, this study has demonstrated that the temporal resolution of rainfall inputs could have much impact on daily streamflow simulations by SWAT in the large-sized Ru River Basin. Generally, the sub-daily SWAT model was better at simulating peak flows during the flood season, which is a critical factor in the formulation of sound strategies and programs for flood control and water security in river basins. In addition, the daily and sub-daily models have also depicted different hydrological processes in the study region. For example, the sub-daily model estimated that $58 \%$ of streamflow was contributed by baseflow while the 
daily model gave an estimate of $34 \%$. The differences in hydrological process simulations could also have significant impact on using the SWAT model to simulate the pollutant transport and transformation processes in the river basin such as the nitrification and denitrification of nitrogen, which surely merits more in-depth investigations in the future.

Despite its overall better performance in daily streamflow simulation in the Ru River Basin, the sub-daily SWAT model has exhibited higher parameter sensitivity and more prediction uncertainty. Due to the limited availability of sub-daily rainfall projection results in China, this study has not compared and evaluated the uncertainty associated with the SWAT model projections of future streamflow. In view of the limited SWAT studies utilizing the sub-daily rainfall inputs and their potentially significant impacts on the simulations of hydrological process, streamflow, and pollutant transport, there is an imperative need for more SWAT studies incorporating precipitation data of higher temporal resolution in river basins of different environmental conditions, so as to comprehensively assess the impacts of the temporal resolution of rainfall inputs on SWAT modeling results and the implications to the sustainable management of the river basin's water resources as well as non-point source water pollution control. Meanwhile, reliable techniques for the downscaling, evaluation, and bias-correction of GCM outputs to the sub-daily resolution are needed for studying the impacts of climate change in river basins where sub-daily models are more applicable.

\section{Acknowledgements}

The authors gratefully acknowledge the financial support provided by Chinese Natural Science Foundation (41201191), Chinese Ministry of Education New Faculty Fund (20120071120034), and Fudan University Tyndall Center Project (FTC98503B04). We also acknowledge the CORDEX-East Asia Databank, which is responsible for the CORDEX dataset, and we thank the National Institute of Meteorological Research (NIMR), three universities in the Republic of Korea (Seoul National University, Yonsei University, Kongju National University) and other cooperative research institutes in East Asia region for producing and making available their model output. 


\section{References}

Abbaspour, KC (2011). SWAT-CUP4: Swat calibration and uncertainty programs - a user manual. Swiss Federal Institute of Aquatic Science and Technology, Eawag.

Abbaspour, KC, Johnson, CA, and van Genuchten, MT (2004) Estimating uncertain flow and transport parameters using a sequential uncertainty fitting procedure. Vadose Zone J 3:1340-1352.

Akhavan, S, Abedi-Koupai, J, Mousavi, S-F, Afyuni, M, Eslamian, S-S and Abbaspour, KC (2010) Application of SWAT model to investigate nitrate leaching in Hamadan-Bahar watershed, Iran. Agri Ecosys Environ 139: 675-688.

Arnold, JG and Allen, PM (1999) Automated methods for estimating baseflow and ground water recharge from streamflow records. J Am Water Resour Assoc 35(2): 411-424.

Arnold, JG, Moriasi, DN, Gassman, PW, Abbaspour, KC, White, MJ, Srinivasan, R, Santhi, C, Harmel, RD, Griensven, Av, Liew, MWV, Kannan, N and Jha, MK (2014) SWAT: Model use, calibration, and validation. Trans ASABE 55(4): 1491-1508.

Bekele, EG and Knapp, HV (2010) Watershed modeling to assessing impacts of potential climate change on water supply availability. Water Resour Manag 24(13): 3299-3320.

Cerro, I, Antiguedad, I, Srinavasan, R, Sauvage, S, Volk, M and Sanchez-Perez, JM (2014) Simulating land management options to reduce nitrate pollution in an agricultural watershed dominated by an alluvial aquifer. J Environ Qual 43(1): 67-74.

Davies, T, M., Cullen, JP, Malcolm, AJ, Mawson, MH, Staniforth, A, White, AA and Wood, N (2005) A new dynamical core for the met office's global and regional modeling of the atmosphere. Quart J Roy Meteor Soc 131: 1759-1782.

Dessu, SB and Melesse, AM (2013) Impact and uncertainties of climate change on the hydrology of the Mara river basin, Kenya/Tanzania. Hydrol Process 27(20): 2973-2986.

Du, H, Xia, J, Zeng, S, She, D and Liu, J (2014) Variations and statistical probability characteristic analysis of extreme precipitation events under climate change in Haihe River Basin, China. Hydrol Process 28: 913-925.

Duan, K, and Mei, Y (2014) Comparison of meteorological, hydrological and agricultural drought responses to climate change and uncertainty assessment. Water Resour Manage 28:5039-5054

Fohrer, N, Dietrich, A, Kolychalow, O and Ulrich, U (2014) Assessment of the environmental fate of the herbicides flufenacet and metazachlor with the SWAT model. J Environ Qual 43(1): 75-85.

Gao, C, Zhang, Z, Chen, S, Liu, Q (2014) The high-resolution simulation of climate change model under RCP4.5 scenarios in the Huaihe River Basin (Chinese). Geogr Res 33(3): 467-477.

Gassman, PW, Reyes, MR, Green, CH and Arnold, JG (2007) The soil and water assessment tool: Historical development, applications, and future research directions. Trans ASABE 50(4): 
1211-1250.

Gassman, PW, Sadeghi, AM and Srinivasan, R (2014) Applications of the SWAT model special section: Overview and insights. J Environ Qual 43: 1-8.

Geza, M and McCray, JE (2008) Effects of soil data resolution on SWAT model stream flow and water quality predictions. J Environ Manage 88(3): 393-406.

Glavan, M, White, S and Holman, IP (2011) Evaluation of river water quality simulations at a daily time step - experience with swat in the Axe catchment, UK. Clean-Soil Air Water 39(1): 43-54.

Gong, YW, Shen, ZY, Liu, RM, Hong, Q and Wu, X (2012) A comparison of single- and multi-gauge based calibrations for hydrological modeling of the Upper Daning River watershed in China's three gorges reservoir region. Hydrol Res 43(6): 822-832.

Henan Province Soil Survey Office. 1995. Atlas of the Soils in Henan Province. Chinese Agriculture Press. Beijing, China.

Hu, Y, Liu, Y, Tang, H, Xu, Y and Pan, J (2014) Contribution of drought to potential crop yield reduction in a wheat-maize rotation region in the North China Plain. J Integr Agr 13(7): 1509-1519.

Jeong, J, Kannan, N, Arnold, JG, Glick, R, Gosselink, L, Srinivasan, R and Harmel, RD (2011) Development of sub-daily erosion and sediment transport algorithms for SWAT. Trans ASABE 54 (5): 1685-1691.

Jha, MK and Gassman, PW (2014) Changes in hydrology and streamflow as predicted by a modelling experiment forced with climate models. Hydrol Process 28(5): 2772-2781.

Kannan, N, White, SM, Worrall, F and Whelan, MJ (2007) Sensitivity analysis and identification of the best evapotranspiration and runoff options for hydrological modelling in SWAT-2000. J Hydrol 332(3-4): 456-466.

Krause, P, Boyle, DP and Base, F (2005) Comparison of different efficiency criteria for hydrological model assessment. Adv Geosci 5: 89-97.

Li, FP, Xu, ZX, Liu, WF and Zhang, YQ (2014) The impact of climate change on runoff in the yarlung tsangpo river basin in the Tibetan plateau. Stoch Environ Res Risk Assess 28(3): 517-526.

Lu, GH, Xiao, H, Wu, ZY, Zhang, SL, Li, Y( 2013) Assessing the Impacts of future climate change on hydrology in Huang-Huai-Hai Region in China using the PRECIS and VIC Models. J. Hydrol. Eng. 18: 1077-1087.

Lv, M, Hu, T and Dan, L (2014) Daily streamflow simulation in a small-scale farmland catchment using modified SWAT model. Trans ASABE 57(1): 31-41.

Maharjan, GR, Park, YS, Kim, NW, Shin, DS, Choi, JW, Hyun, GW, Jeon, J-H, Ok, YS and Lim, KJ 
(2013) Evaluation of SWAT sub-daily runoff estimation at small agricultural watershed in Korea. Front Environ Sci Eng 7(1): 109-119.

Martin, GM, Ringer, MA, Pope, VD, Jones, A, Dearden, C and Hinton, TJ (2006) The physical properties of the atmosphere in the new hadley centre global environmental model (HADGEM1). Part I: Model description and global climatology. J Clim 19: 1274-1302.

Masih, I, Maskey, S, Uhlenbrook, S, and Smakhtin, V (2011) Assessing the impact of areal precipitation input on streamflow simulations using the SWAT model. J Am Water Resour Assoc 47: 179-195.

Mishra, A and Kar, S (2012) Modeling hydrologic processes and nps pollution in a small watershed in subhumid subtropics using SWAT. J Hydrol Eng 17(3): 445-454.

Moriasi, DN and Starks, PJ (2010) Effects of the resolution of soil dataset and precipitation dataset on SWAT2005 streamflow calibration parameters and simulation accuracy. J Soil Water Conserv 65(2): 63-78.Oeurng, C, Sauvage, S and Sanchez-Perez, JM (2011) Assessment of hydrology, sediment and particulate organic carbon yield in a large agricultural catchment using the SWAT model. J Hydrol 401(3-4): 145-153.

Oliver, CW, Radcliffe, DE, Risse, LM, Habteselassie, M, Mukundan, R, Jeong, J and Hoghooghi, N (2014) Quantifying the contribution of on-site wastewater treatment systems to stream discharge using the SWAT model. J Environ Qual 43(2): 539-548.

Paschalis, A, Fatichi, S, Molnar, P, Rimkus, S and Burlando, P (2014) On the effects of small scale space-time variability of rainfall on basin flood response. J Hydrol 514: 313-327.

Praskievicz, S and Bartlein, P (2014) Hydrologic modeling using elevationally adjusted NARR and NARCCAP regional climate-model simulations: Tucannon River, Washington. J Hydrol 517: 803-814.

Prescott, JA (1940) Evaporation from water surface in relation to solar radiation. Trans Roy Soc S Austra 40: 114-118.

Rouhani, H, Willems, P, Wyseure, G and Feyen, J (2007) Parameter estimation in semi-distributed hydrological catchment modelling using a multi-criteria objective function. Hydrol Process 21(22): 2998-3008.

Saha, PP, Zeleke, K and Hafeez, M (2014) Streamflow modeling in a fluctuant climate using SWAT: Yass river catchment in Southeastern Australia. Environ Earth Sci 71(12): 5241-5254.

Saxton, KE and Willey, PH (2005) The SPAW model for agricultural field and pond hydrologic simulation. In VP Singh and D Frevert. (Eds). Mathematical modeling of watershed hydrology, CRC Press LLC.

Shi, P, Ma, XX, Hou, YB, Li, QF, Zhang, ZC, Qu, SM, Chen, C, Cai, T and Fang, XQ (2013) Effects 
of land-use and climate change on hydrological processes in the upstream of Huai River, China. Water Resour Manag 27(5): 1263-1278.

Shi, XZ, Yu, DS, Warner, ED, Pan, XZ, Petersen, GW, Gong, ZG and Weindorf, DC (2004) Soil database of 1:1,000,000 digital soil survey and reference system of the Chinese genetic soil classification system. Soil Survey Horizons 45(4): 129-136.

Shi, XZ, Yu, DS, Xu, SX, Warner, ED, Wang, HJ, Sun, WX, Zhao, YC and Gong, ZT (2010) Cross-reference for relating genetic soil classification of china with WRB at different scales. Geoderma 155(3-4): 344-350.

Wagner, PD, Fiener, P, Wilken, F, Kumar, S and Schneider, K (2012) Comparison and evaluation of spatial interpolation schemes for daily rainfall in data scarce regions. J Hydrol 464: 388-400.

Wang, G and Xia, J (2010) Improvement of swat2000 modelling to assess the impact of dams and sluices on streamflow in the huai river basin of China. Hydrol Process 24: 1455-1471.

Wang, HL, Wu, ZN and Hu, CH (2015) A comprehensive study of the effect of input data on hydrology and non-point source pollution modeling. Water Resour Manag 29: 1505-1521.

Wu, H and Chen, B (2015) Evaluating uncertainty estimates in distributed hydrological modeling for the Wenjing River watershed in China by GLUE, SUFI-2, and ParaSol methods. Ecological Engineering 76: 110-121.

Yang, J, Abbaspour, KC, Reichert, P, and Yang, H (2008) Comparing uncertainty analysis techniques for a SWAT application to Chaohe Basin in China. J Hydrology 358(1-2):1-23.

Yoon, S, Jeong, C and Lee, T (2014) Flood flow simulation using CMAX radar rainfall estimates in orographic basins. Meteorol Appl 21: 596-604.

Yu, DS, Shi, XZ, Wang, HJ, Sun, WX, Liu, QH and Zhao, YC (2007a) Regional patterns of soil organic carbon storages in China. J Environ Manag 85: 680-689.

Yu, DS, Shi, XZ, Wang, HJ, Sun, WX, Warner, ED and Liu, QH (2007b) National scale analysis of soil organic carbon storage in china based on Chinese soil taxonomy. Pedosphere 17(1): 11-18.

Zhang, X, Srinivasan, R and Hao, F (2007) Predicting hydrologic response to climate change in the Luohe river basin using the SWAT model. Trans ASABE 50(3): 901-910.

Zhang, Y, Xia, J, Shao, Q and Zhai, X (2013) Water quantity and quality simulation by improved swat in highly regulated Huai River basin of China. Stoch Environ Res Risk Assess 27: 11-27.

Zhou, J, Liu, Y, Guo, H and He, D (2014) Combining the SWAT model with sequential uncertainty fitting algorithm for streamflow prediction and uncertainty analysis for the Lake Dianchi Basin, China. Hydrol. Process 28: 521-533.

Zuo, D, Wang, Y and Chen, J (1963) Regional spatial patterns of solar radiation in China (Chinese). ACTA Metero SINICA 33(1): 78-95. 


\section{List of figures}

Fig. 1 Study region.

Fig. 2 Spatial distribution of land use and soil types.

Fig. 3 Boxplots of annual precipitation at 28 rainfall stations from 2001 to 2011. In each boxplot, the whisker ranges from the minimum to maximum, while the box ranges from the first quartile to the third quartile. The symbol $\square$ represents the mean, and $\times$ 's represent the 1 and 99 percentiles.

Fig. 4 Spatial distribution of average annual precipitation.

Fig. 5 Observed and simulated daily streamflow during the calibration (2005-2008) and validation (2009-2011) periods: (a) Daily model simulation results at the Lixin station; (b) Sub-daily model simulation results at the Lixin station; (c) Daily model simulation results at the Luzhuang station; (d) Sub-daily model simulation results at the Luzhuang station.

Fig. 6 Comparison of the simulated peak flows (99 percentile) between the daily and sub-daily SWAT models: (a) Lixin station; (b) Luzhuang station.

Fig. 7 Comparison of the simulated daily streamflow at the Luzhuang station by the daily and sub-daily SWAT models on raining days when daily streamflow observations fell between 1 and 50 $\mathrm{m}^{3} / \mathrm{s}$.

Fig. 8 Comparison of the simulated monthly maximum daily streamflow during the flood season till 2050 by the daily and sub-daily SWAT models at the outlet of the sub-basin located above the Suyahu reservoir. 
Table 1 Selected recent SWAT applications on daily streamflow simulation

\begin{tabular}{|c|c|c|c|c|c|c|c|c|}
\hline \multirow{2}{*}{ Reference } & \multirow{2}{*}{ Watershed } & \multirow{2}{*}{$\begin{array}{l}\text { Drainage Area } \\
\qquad\left(\mathrm{km}^{2}\right)\end{array}$} & \multicolumn{2}{|c|}{ Time Period } & \multicolumn{2}{|c|}{ Calibration } & \multicolumn{2}{|c|}{ Validation } \\
\hline & & & Calib. & Valid. & $\overline{\mathrm{R}^{2}}$ & NSE & $\mathrm{R}^{2}$ & NSE \\
\hline Akhavan et al. (2010) & $\begin{array}{l}\text { Hamadan-Bahar } \\
\text { watershed (Iran) }\end{array}$ & 2460 & $2000-2008$ & 1992-1999 & $0.38-0.83$ & $0.27-0.77$ & $0.27-0.75$ & $-0.01-0.70$ \\
\hline Bekele and Knapp (2010) & Fox River （U.S.） & 6885 & $1960-1969$ & 1950-1959 & & $0.55-0.65$ & & $0.46-0.67$ \\
\hline Cerro et al. (2014) & Alegria Watershed (Spain) & 53 & $2009-2010$ & 2010-2011 & 0.72 & 0.68 & 0.52 & 0.49 \\
\hline Dessu and Melesse (2013) & $\begin{array}{c}\text { Mara River } \\
\text { (Kenya/Tanzania) }\end{array}$ & 13750 & $1978-1982$ & 1988-1992 & 0.69 & 0.68 & 0.44 & 0.43 \\
\hline Fohrer et al. (2014) & $\begin{array}{l}\text { Kielstau Watershed } \\
\text { (Germany) }\end{array}$ & 50 & 2003-2005 & 2006-2009 & 0.84 & 0.83 & 0.77 & 0.76 \\
\hline Geza and McCray (2008) & Turkey Creek (U.S.) & 126 & 1998-2001 & & $0.61-0.74$ & $0.27-0.77$ & & $-0.01-0.70$ \\
\hline Glavan et al. (2011) & River Axe (England) & 400 & 1988-1997 & 1998-2005 & 0.62 & 0.62 & 0.53 & 0.47 \\
\hline Gong et al. (2012) & Daning River (China) & 2010 & $2000-2003$ & 2004-2007 & & $0.68-0.85$ & & $0.44-0.80$ \\
\hline Mishra and Kar (2012) & Banha Watershed (India) & 16.95 & 1996 & 2000,2001 & 0.93 & 0.70 & $0.76-0.83$ & $0.62-0.70$ \\
\hline Oeurng et al. (2011) & Save River (France) & 1110 & 1999-2009 & & 0.56 & 0.53 & & \\
\hline Oliver et al. (2014) & Big Haynes Creek (U.S.) & 44 & $2003-2006$ & $2007-2010$ & 0.50 & 0.49 & 0.46 & 0.37 \\
\hline Rouhani et al. (2007) & $\begin{array}{l}\text { Grote Nete River } \\
\text { (Belgium) }\end{array}$ & 383 & $1986-1989$ & 1990-1995 & 0.82 & 0.67 & 0.81 & 0.66 \\
\hline Saha et al. (2014) & Yass River (Australia) & 1597 & 1993-2002 & 2003-2011 & 0.55 & 0.56 & 0.81 & 0.71 \\
\hline Zhang et al. (2007) & Luohe River ( China) & 5239 & $1992-1996$ & $1997-2000$ & 0.82 & 0.65 & 0.74 & 0.54 \\
\hline
\end{tabular}


Table 2 Data inputs for the SWAT model

\begin{tabular}{lll}
\hline \multicolumn{1}{c}{ Data Category } & \multicolumn{1}{c}{ Scale/Extent } & \multicolumn{1}{c}{ Data Sources } \\
\hline DEM & $1: 50,000$ & Chinese National Geomatics Center \\
2005 Land Use/ Land Cover & $1: 100,000$ & Chinese Academy of Science \\
Soil types and soil properties & $1: 1000,000$ & Nanjing Institute of Soil Science; \\
& & Henan Province Soil Survey Office \\
River networks & $1: 250,000$ & (1995); SPAW software \\
Daily weather (1960-2011) & 1 Station (Zhumadian) & Chinese Academy of Science \\
& & Administration \\
Daily and hourly rainfall & 28 Stations ${ }^{*}$ & Chinese Ministry of Water Resources \\
(2001-2011) & & \\
Daily streamflow (2005-2011) & 3 Stations (Lixin, & Chinese Ministry of Water Resources \\
& Luzhuang, and Shakou) & \\
Daily reservoir outflow & 3 Reservoirs (Banqiao, & Chinese Ministry of Water Resources \\
(2005-2011) & Boshan, and Suyahu) & \\
Crop management practices & 116 farmers & Field Survey \\
\hline
\end{tabular}

*The 28 rainfall stations are Banqiao, Boshan, Caibukou, Daheiliuzhuang, Guizhuang, Hexiaodian, Hezhuang, Houmiao, Jialou, Laojun, Linzhuang, Lixin, Luodian, Mayigou, Quesan, Shahedian, Shakou, Shizhuang, Suiping, Taohuadian, Wulizhuang, Xiachen, Xiangheguan, Xiasong, Xiatun, Zangji, Zhugou, and Zhumadian. 
Table 3 Parameters for calibrating the daily and sub-daily SWAT models

\begin{tabular}{|c|c|c|}
\hline Category & Parameter & Description \\
\hline \multirow{2}{*}{ Runoff } & CN2 & Moisture condition II curve number \\
\hline & SURLAG & Surface runoff lag coefficient \\
\hline \multirow{2}{*}{ Plant } & EPCO & Plant uptake compensation factor \\
\hline & CANMX & Maximum canopy storage \\
\hline \multirow{6}{*}{ Groundwater } & ALPHA_BF & Baseflow alpha factor \\
\hline & $G W_{-} D E L A Y$ & Groundwater delay \\
\hline & $G W Q M N$ & Threshold depth of water in the shallow aquifer required for \\
\hline & & return flow to occur \\
\hline & $R E V A P M N$ & $\begin{array}{l}\text { Threshold depth of water in the shallow aquifer for "revap" to } \\
\text { occur }\end{array}$ \\
\hline & $G W \_R E V A P$ & Groundwater "revap" coefficient \\
\hline \multirow{3}{*}{ Soil } & $S O L \_A W C$ & Available water capacity of the soil layer \\
\hline & $S O L \_K$ & Saturated hydraulic conductivity of the soil layer \\
\hline & ESCO & Soil evaporation compensation factor \\
\hline \multirow{4}{*}{ Channel } & $\mathrm{CH} \_\mathrm{NI}$ & Manning's " $n$ " value for the tributary channels \\
\hline & $\mathrm{CH} \_\mathrm{N} 2$ & Manning's " $n$ " value for the main channel \\
\hline & $\mathrm{CH} \_\mathrm{Kl}$ & Effective hydraulic conductivity in tributary channel alluvium \\
\hline & $\mathrm{CH}_{-} \mathrm{K} 2$ & Effective hydraulic conductivity in main channel alluvium \\
\hline
\end{tabular}


Table 4 Comparison of parameter values and sensitivities between the daily and sub-daily SWAT models

\begin{tabular}{|c|c|c|c|c|c|c|c|c|c|}
\hline \multirow{3}{*}{ Parameter } & \multicolumn{3}{|c|}{ Initial Models } & \multicolumn{6}{|c|}{ Calibrated Models } \\
\hline & \multirow{2}{*}{ Range } & \multicolumn{2}{|c|}{ P Value } & \multicolumn{3}{|c|}{ Daily } & \multicolumn{3}{|c|}{ Sub-Daily } \\
\hline & & Daily & Sub-Daily & Value & Range & P Value & Value & Range & $\mathrm{P}$ Value \\
\hline CN2_AGRR & $67-99$ & 0.00 & 0.00 & $68.6-90.6^{\mathrm{a}}$ & $68.5-92$ & 0.22 & $75.8-97.8^{\mathrm{a}}$ & $75-98$ & 0.00 \\
\hline CN2_FRST & $43-87$ & 0.00 & 0.00 & $45.2-84.2^{\mathrm{a}}$ & $43-85$ & 0.06 & $46.6-85.6^{\mathrm{a}}$ & $45-86$ & 0.00 \\
\hline CN2_URML & $62-92$ & 0.89 & 0.06 & $64.1-79.1^{\mathrm{a}}$ & $62-81$ & 0.79 & $73.3-88.3^{\mathrm{a}}$ & $67-89$ & 0.00 \\
\hline SURLAG & $1-10$ & 0.00 & 0.00 & 2.3 & $1-5$ & 0.00 & 5.1 & $4.3-10.7$ & 0.00 \\
\hline EPCO & $0.85-1$ & 0.00 & 0.00 & 0.9 & $0.88-0.9$ & 0.00 & 0.9 & $0.89-0.92$ & 0.00 \\
\hline CANMX_AGRR & $1-10$ & 0.00 & 0.72 & 6.5 & $4-7$ & 0.54 & 7.4 & $5.5-7.7$ & 0.00 \\
\hline CANMX_FRST & $5-25$ & 0.13 & 0.00 & 10.5 & $4-13$ & 0.19 & 23.3 & $16-25$ & 0.00 \\
\hline ALPHA_BF & $0.03-0.1$ & 0.00 & 0.00 & 0.03 & $0.02-0.06$ & 0.09 & 0.06 & $0.03-0.07$ & 0.00 \\
\hline GW_DELAY & $10-300$ & 0.36 & 0.00 & 43.9 & $20-45$ & 0.45 & 215.8 & $195-245$ & 0.00 \\
\hline GWQMN & $10-150$ & 0.46 & 0.00 & 54.1 & $39-57$ & 0.40 & 83.8 & $75-115$ & 0.29 \\
\hline REVAPMN & $10-200$ & 0.34 & 0.00 & 141.6 & $125-145$ & 0.50 & 69.1 & $45-70$ & 0.02 \\
\hline GW_REVAP & $0.02-0.2$ & 0.05 & 0.00 & 0.03 & $0.02-0.04$ & 0.73 & 0.16 & $0.13-0.17$ & 0.00 \\
\hline SOL_AWC & $0.12-0.36$ & 0.00 & 0.00 & $0.15-0.34^{\mathrm{b}}$ & $0.14-0.35$ & 0.48 & $0.15-0.35^{\mathrm{b}}$ & $0.14-0.36$ & 0.00 \\
\hline SOL_K & $1.6-901.3$ & 0.13 & 0.00 & $2.0-895.1^{\mathrm{b}}$ & $1.9-895.1$ & 0.74 & $1.8-801.9^{\mathrm{b}}$ & $1.7-808.1$ & 0.00 \\
\hline ESCO & $0.85-1$ & 0.00 & 0.00 & 0.94 & $0.93-0.97$ & 0.00 & 0.99 & $0.95-0.99$ & 0.00 \\
\hline CH_N1 & $0.19-0.32$ & 0.00 & 0.23 & 0.29 & $0.27-0.31$ & 0.02 & 0.26 & $0.23-0.26$ & 0.02 \\
\hline CH_N2 & $0.035-0.049$ & 0.41 & 0.07 & 0.047 & $0.046-0.048$ & 0.38 & 0.043 & $0.042-0.046$ & 0.49 \\
\hline CH_K1 & $0-50$ & 0.00 & 0.00 & 1.0 & $0-3$ & 0.15 & 4.5 & $2.7-8.1$ & 0.02 \\
\hline CH_K2 & $0-50$ & 0.00 & 0.00 & 12.3 & $0-15$ & 0.90 & 5.4 & $0-8.4$ & 0.00 \\
\hline
\end{tabular}

${ }^{a}$ Show the range of the calibrated values for different hydrological groups.

${ }^{\mathrm{b}}$ Show the range of the calibrated values for different soil types and soil layers. 
Table 5 Model evaluation statistics for the calibration and validation periods at the three hydrological stations

\begin{tabular}{|c|c|c|c|c|c|c|c|c|}
\hline \multirow{3}{*}{ Station } & \multicolumn{4}{|c|}{ Calibration (2005-2008) } & \multicolumn{4}{|c|}{ Validation (2009-2011) } \\
\hline & \multicolumn{2}{|c|}{ Daily } & \multicolumn{2}{|c|}{ Sub-Daily } & \multicolumn{2}{|c|}{ Daily } & \multicolumn{2}{|c|}{ Sub-Daily } \\
\hline & $\mathrm{R}^{2}$ & NSE & $\mathrm{R}^{2}$ & NSE & $\mathrm{R}^{2}$ & NSE & $\mathrm{R}^{2}$ & $\overline{N S E}$ \\
\hline Lixin & 0.59 & 0.59 & 0.74 & 0.74 & 0.70 & 0.70 & 0.85 & 0.85 \\
\hline Luzhuang & 0.47 & 0.47 & 0.75 & 0.76 & 0.27 & 0.29 & 0.70 & 0.71 \\
\hline Shakou & 0.93 & 0.93 & 0.92 & 0.92 & 0.96 & 0.96 & 0.92 & 0.94 \\
\hline
\end{tabular}

